\section{Is artificial life moving any closer?}

\author{
Genesis Redux \\ edited by Jessica Riskin \\ University of Chicago Press: 2007. 389 pp. \\ $\$ 25, \notin 16$

\section{Beyond Human} \\ by Gregory Benford and Elisabeth \\ Malartre \\ Tor/Forge: 2007. 272 pp. \$24.95
}

\section{Greg Bear}

Three vinyl toys stand on my office bookshelf: the Golem, Frankenstein's monster and the Terminator - a reminder that automatons of the imagination have been with us for a long time. The synthesis of life in both the past and future is discussed in two new books that open a window on to artificial life, enhanced life and robots. Genesis Redux gathers together papers from a rousing academic conference held in Stanford in 2003, and Beyond Human offers a critical but enthusiastic view from a physics and biological perspective.

The strength of Genesis Redux lies in its scholarship and range of topics. Clockworks, mechanical toys and their influence on biological concepts are presented in fascinating detail. Joan Landes introduces us to the Hoffmanesque works of Jacques de Vaucanson's feminine flautist and (excreting) duck, and to the flayed, preserved and posed cadavers, the écorchés, of Jean-Honoré Fragonard: there is a dancing fetus and a very naked man staring in horror, jawbone in hand. Landes delivers a lively analysis of our reactions to the abject and uncanny, the frisson so beloved by fans of Dr Frankenstein.

Philosophers and scientists of the day before the younger Darwin - were already deeply concerned with the analogies that could be drawn between mechanism and creature. Were they useful, or misleading? The question remains in play. And life and thought are difficult to simulate (as Drosselmeyer, the toy-maker and magician from The Nutcracker, would testify) - but even harder to implement.

Less obviously connected with artificial life is an essay by Elliott Sober on sex ratios in human populations, and whether they point to a benevolent creator or to mere chance. Therein lies a profound question: if life is the result of a creative act, then is all life 'artificial'? What if there is, as godless evolution surely implies, self-creation? Are we not then our own artefacts, mechanisms of joy and magic - and does that wrap us in another illusion, like the beauty of a clockwork flute-player?

Norton Wise discusses the masculine and feminine Victorian categorization of men as prime mover - 'engine' - and women as 'mechanism'. And yet no mention is made of Mary Shelley, the most influential engine of artificial life in history. Likewise, in most of these discussions a paucity of references to key literature prevails. H. G. Wells's The Time Machine is cogently discussed, but not The Island of Doctor Moreau, The New Accelerator or The Food of the Gods. Completely neglected is Robert A. Heinlein, creator of Mike, the first computer graphic artificial intelligence, in The Moon Is a Harsh Mistress - though many of Mike's children peer out of its illustrations.

Bernadette Bensaude-Vincent gives a brief history of nanotechnology and its key analogies, drawn from molecular biology. In 1961, Richard Feynman was intrigued by the possibility of increasingly tiny assemblers. Eric Drexler hopes to emulate organic molecules in more enduring form. But the present bull market for nanotech seems to have devolved into innovations in materials science, rather than a quest to create tiny self-replicating machines. The same thing happened with artificial intelligence and neural network theory — high aspirations became mired in frustration, then subsumed by lower-level research and industrial buzzwords, lofty goals redefined.

Genesis Redux takes the time to shed light on areas I would not naturally consider, and thus enlightens and expands the topic. Its cautious perspective - the enthusiasms of the past considered in the sober light of history - provides a useful counterpoint to our next book.

In Beyond Human, Gregory Benford and Elisabeth Malartre (a husband-and-wife team) take a more personal, promotional approach, and deftly give credit to the actual creators and thinkers: scientists, engineers, philosophers, writers and film-makers. Interviews with pioneers and participants in enhancement research, robotics and engineering, and informed perspectives on the theory, economics and actuality of life extension, give Beyond Human the flavour of a tourist guide to the future, conducted by natives, rather than a missionary's critical, hands-off examination.

The authors detail the experiences of our true cyborgs - disabled people whose hightech prosthetics may make them more competitive than their able peers. They try to answer technical questions about the smallest size attainable for nanobot fingers and the practical limits of very small manipulators, and by implication, tiny intelligence devices. Their limiting answers could stimulate and irritate researchers into devising clever workarounds.

As biology and synthetic biology converge, and true artificial life becomes more and more feasible, the power for change will exceed that of nuclear energy. The fire of life is more subtle and pervasive and, through mass production

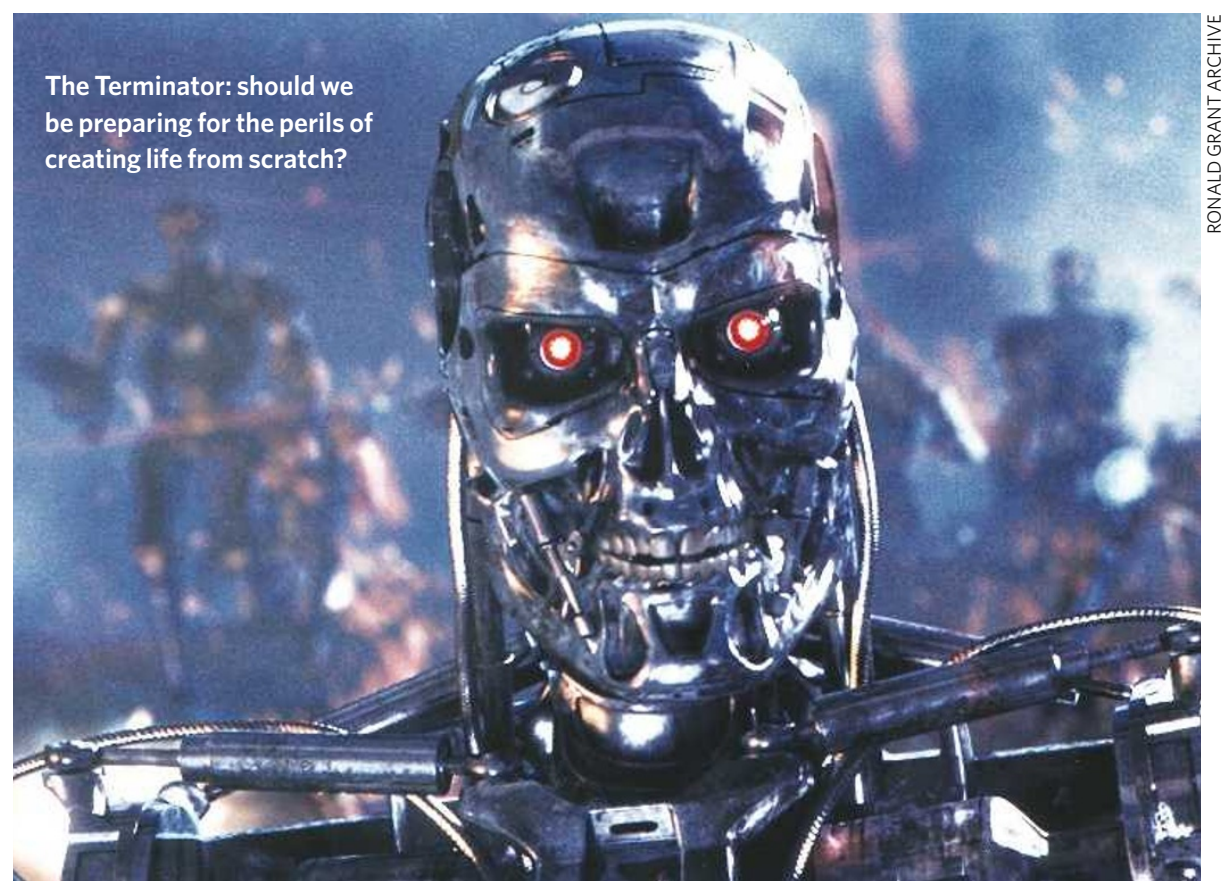

and the internet, is being made available not just to well-funded government institutions but to private individuals. Training and research at secondary school will be essential for the biotech future, but could put dangerous tools into the hands of those whose aim is mass destruction - be they terrorists or domestic bigots. Institutions and journals should begin planning the necessary precautions; public discussion and professional prudence are essential. One terrorist incident could shut down basic research for years.

Together, these books serve up a feast with many side-dishes. The future is not behind us. Full of danger and potential, it is still unexplored territory, waiting to be rediscovered after our early encounters in nightmares and daydreams.

Greg Bear is the author of Quantico, Darwin's Radio and Queen of Angels. He can be contacted at www.gregbear.com. 